\title{
Investigation of Failure Behavior of HRB335 steel due to Crevice Corrosion in Concrete Using Electrochemical Method
}

\author{
Gang Li, Di Yin, Jianrong Pang \\ College of Civil Engineering, Cangzhou Jiaotong College, Hebei Cangzhou 061199, China \\ *E-mail: teacher_li08@163.com
}

Received: 21 August 2021 / Accepted: 17 September 2021 / Published: 10 October 2021

\begin{abstract}
The corrosion of reinforcements in the concrete crevice is a crucial factor affecting the safety and stability of concrete, especially in an environment containing chloride ions. Cathodic protection is one of the key methods to protect reinforcements in concrete. In this paper, based on wedge crevice corrosion experimental device, the corrosion behaviour of reinforcement in concrete crevice structure and the effectiveness of cathodic protection were studied involving electrochemical parameters, corrosion rate and electrochemical impedance spectroscopy. The results showed that the anode area was located near the opening. With the development of the crevice depth, the corrosion form changed from general corrosion to pitting corrosion and from the anode area to the cathode area. The cathodic protection made the anode area move forward in the crevice, intensified the corrosion degree of the anode area, and pitted corrosion at sample $6 \#$ in the deepest crevice.
\end{abstract}

Keywords: Concrete; Cathodic protection; Electrochemical method; Wedge crevice device

\section{$\underline{\text { FULL TEXT }}$}

(C) 2021 The Authors. Published by ESG (www.electrochemsci.org). This article is an open access article distributed under the terms and conditions of the Creative Commons Attribution license (http://creativecommons.org/licenses/by/4.0/). 